\title{
Confocal Raman microscope mapping as a tool to describe different mineral and organic phases at high spatial resolution within marine biogenic carbonates: case study on Nerita undata (Gastropoda, Neritopsina)
}

\author{
G. Nehrke ${ }^{1}$ and J. Nouet ${ }^{2}$ \\ ${ }^{1}$ Alfred Wegener Institute for Polar and Marine Research, Am Handelshafen 12, 27570 Bremerhaven, Germany \\ ${ }^{2}$ University Paris Sud, IDES UMR 8148, bâtiment 504, campus universitaire, 91405 Orsay cedex, France
}

Received: 20 May 2011 - Published in Biogeosciences Discuss.: 9 June 2011

Revised: 10 November 2011 - Accepted: 7 December 2011 - Published: 20 December 2011

\begin{abstract}
Marine biogenic carbonates formed by invertebrates (e.g. corals and mollusks) represent complex composites of one or more mineral phases and organic molecules. This complexity ranges from the macroscopic structures observed with the naked eye down to sub micrometric structures only revealed by micro analytical techniques. Understanding to what extent and how organisms can control the formation of these structures requires that the mineral and organic phases can be identified and their spatial distribution related. Here we demonstrate the capability of confocal Raman microscopy applied to cross sections of a shell of Nerita undata to describe the distribution of calcite and aragonite including their crystallographic orientation with high lateral resolution $(\sim 300 \mathrm{~nm})$. Moreover, spatial distribution of functional groups of organic compounds can be simultaneously acquired, allowing to specifically relate them to the observed microstructures. The data presented in this case study highlights the possible new contributions of this method to the description of modalities of Nerita undata shell formation, and what could be expected of its application to other marine biogenic carbonates. Localization of areas of interest would also allow further investigations using more localized methods, such as TEM that would provide complementary information on the relation between organic molecules and crystal lattice.
\end{abstract}

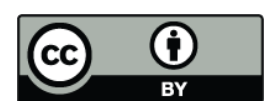

Correspondence to: G. Nehrke (gernot.nehrke@awi.de)

\section{Introduction}

Calcium carbonates formed by marine calcifying organisms (e.g. corals and mollusks) received much attention in the field of biogeosciences during the last decades. On the one hand they represent important proxy archives (e.g. oxygen isotopic composition can be used for temperature reconstruction (McCrea, 1950; Urey et al., 1951)) and on the other hand they are affected by the increasing acidification of the ocean due to increasing atmospheric $\mathrm{CO}_{2}$ concentrations (Royal Society, 2005).

It has long been shown that these biogenic carbonates constitute complex composites of organic and inorganic components (Gregoire, 1960; Crenshaw, 1972). As demonstrated by previous studies using Scanning Electron Microcopy (SEM), Transmission Electron Microscopy (TEM), and Atomic Force Microscopy (AFM), organic compounds are incorporated within the mineral phase down to the submicrometer scale (Mutvei, 1969; Weiner and Traub, 1984). Apart from the fact that these organic molecules are intimately associated to the mineral phase within biogenic carbonates, it is poorly understood to what extent these molecules are involved in the control of mineralogy and shape during the biomineralization processes. Thus, the identification of the organic molecules and their spatial distribution within the biogenic carbonate is the basic step for a processed based understanding of biomineralization.

The use of various dyes or etchings together with light microscopy, SEM, or TEM can give some information on the spatial distribution of organic structures but without a chemical characterization of the organic components (Cuif et al.,

Published by Copernicus Publications on behalf of the European Geosciences Union. 
2011). Methods like synchrotron based $\mathbf{X}$-ray Absorption Near Edge Structure (XANES) or Time Of Flight-Secondary Ion Mass Spectroscopy (TOF-SIMS) can give chemical information about organic compounds with high spatial resolution (Cusack et al., 2008; Dauphin et al., 2008; Heim et al., 2009; Dauphin et al., 2010; Farre et al., 2011), but are either difficult to access (XANES) or prone to contamination (TOFSIMS). Extracts of organic compounds from biogenic materials allow a better characterization of their composition, but nothing can be said about their spatial distribution (Krampitz et al., 1976; Samata et al., 1980; Dauphin and Denis, 2000; Farre and Dauphin, 2009).

Raman spectroscopy is a method, which allows determining many inorganic and organic compounds. The Raman signal measured, results from the interaction of monochromatic light with molecular vibrations (inelastic light scattering). Confocal Raman microscopy (CRM) using a laser as source for photons provides a high spatial resolution (down to $\sim 250 \mathrm{~nm}$ ) and is therefore ideally suited for the investigation of biogenic minerals (Melancon et al., 2005; BorzeckaProkop et al., 2007; Hild et al., 2008). The high efficiency of modern CRM systems equipped with automated scanning stages make it possible to map whole sample areas. The datasets obtained can contain up to a few hundred thousand spectra, from, which the areal distribution of mineral phases can be reconstructed. In addition crystallographic parameters such as crystallinity and crystal orientation can be constrained. Simultaneously, the biochemical composition can be mapped and related to the microstructural observations. In this regard, CRM mapping represents a very integrated and unique method to address the wide range of questions, which are regularly raised in studies on biogenic structures.

In order to demonstrate what results can be achieved using CRM mapping on biogenic carbonates, this case study has been carried out on the shell of Nerita undata (Gastropoda, Neritopsina). This taxa is indeed representative of the complexity that can usually be found within molluscan shells, as it presents both simple and complex 3-D microstructural architectures with homogeneous/prismatic and crossed-lamellar layers, as well as different mineral phases (calcite and aragonite) and organic compounds.

\section{Material and methods}

\subsection{Specimen Nerita undata}

A Nerita undata (Linnaeus, 1758) (Gastropoda, Neritopsina) shell (Fig. 1a) has been collected at the Tuamotu Islands, French Polynesia. The shell is composed of an outer calcitic and an inner aragonitic layer (Fig. 1b-c). The calcite layer is usually described as composed of highly irregular, very fine and undulating prisms (Bøggild, 1930). The aragonite layer is crossed-lamellar.
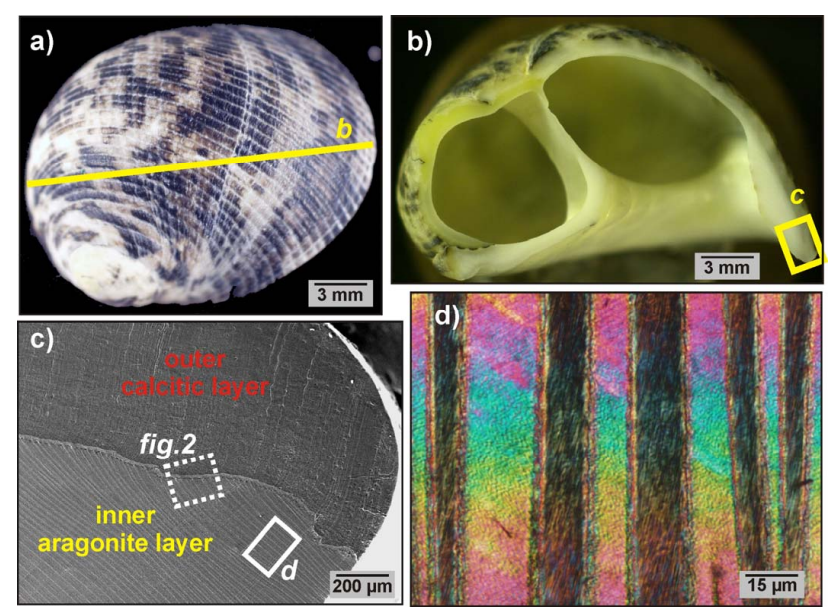

Fig. 1. (a) Picture showing the shell of Nerita undata. Line indicates where the specimen was cut. (b) Cross section of the shell along radial axis (the square labeled "c" indicates the area shown in Fig. 1c). (c) SEM micrograph of a section across the outer lip close to the aperture of the shell. The dotted-square indicates the approximate orientation of the scans of Fig. 2b-e, 3a-f, and $4 b-c$, and the plain square the orientation of 1d. (d) Thin section of the aragonitic crossed lamellar structure forming the inner layer of the shell observed using polarized light microscopy (with crossed polars).

Crossed-lamellar is undoubtedly the microstructure most commonly found in both gastropods and bivalves shells (Bøggild, 1930; Taylor et al., 1969), although many studies on biocrystallization mechanisms have been focused on taxa presenting nacreous and/or prismatic layers (Travis, 1968; Nakahara and Bevelander, 1971; Nudelman et al., 2006; Dauphin et al., 2008). It presents a complex three dimensional architecture, composed of interlaced units at several distinct orders of magnitude. Although many speciesspecific variations exist in size, shape, and orientation, the basic pattern of crossed-lamellar structures is identical. The largest structural unit (termed first order lamellae) is usually described as $10-20 \mu \mathrm{m}$ large lamellae, showing alternating crystallographic orientation every two lamellae (Bøggild, 1930; Kobayashi, 1964). They are themselves composed of $200 \mathrm{~nm}$ thick sheet-like arrangements (termed second order lamellae) of individual rods (which are themselves termed third order lamellae (Kobayashi and Akai, 1994). The third order rods usually dip in opposite directions between two consecutive first order lamellae, with a constant angle that is taxa-related (Taylor et al., 1969; Wilmot et al., 1992). Nerita undata inner layer displays a simple, continuous and mostly regular crossed-lamellar microstructure; first order lamellae are very regular and straight lined, perpendicularly to the inner border of the shell (Bøggild, 1930). A radial section across the shell (Fig. 1c), which will be perpendicular both to growth layers and first order lamellae, is therefore well suited for micro-structural investigation. In this orientation the typical alternate crystal orientation of first order lamellae 
can be nicely illustrated using Polarized Light Microscopy (PLM) and crossed polars on thin sections ( $\sim 10 \mu \mathrm{m}$ thick): the lamellae presenting the exact same crystallographic orientation are simultaneously extinct and display no birefringence colours (Fig. 1d).

Two radial sections were cut close to the peristome of the shell, on the thick lobe that forms the outer lip (Fig. 1b). A first section was glued on a glass plate, then cut and polished using HERMES water grinding papers (grain size $\mathrm{P} 1200 / \mathrm{P} 2500$ to $\mathrm{P} 4000)$ until a $\sim 10 \mu \mathrm{m}$ thick thin section is obtained (sample used for scans labeled scan1a to scan1c in Table 1). Further thick sections were polished using HERMES water grinding papers (grain size P1200/P2500 to $\mathrm{P} 4000$ ), Buehler diamond polycrystalline suspensions $(3 \mu \mathrm{m}$ and $1 \mu \mathrm{m})$ and finally aluminium oxide suspension $(\sim 0.3 \mu \mathrm{m})$. Sample surface was carefully rinsed using demineralized water (sample used for scans labeled scan2a and scan2b in Table 1).

\subsection{Confocal Raman microscopy}

Raman mapping was done using a WITec alpha $300 \mathrm{R}$ (WITec GmbH, Germany) confocal Raman microscope. Scans with a high spatial resolution are performed using a piezoelectric scanner table having a maximum scan range of $200 \mu \mathrm{m} \times 200 \mu \mathrm{m}$ and a minimum step size of $4 \mathrm{~nm}$ lateral and $0.5 \mathrm{~nm}$ vertical. Large area scans are performed using a motorized scan table having a maximum scan range of up to $2.5 \mathrm{~cm} \times 2.5 \mathrm{~cm}$ and minimum step size of $100 \mathrm{~nm}$. Details on the type of scans performed are given in Table 1. Lasers of two different wavelengths $(532 \mathrm{~nm}$ and $785 \mathrm{~nm}$ ) are used for the scans performed in this study. At each wavelength a dedicated ultra high throughput spectrometer (UHTS 300, WITec, Germany) was used. The spectrometer for $532 \mathrm{~nm}$ excitation wavelengths was used with a grating, $600 / \mathrm{mm}, 500 \mathrm{~nm}$ blaze and the spectrometer for $785 \mathrm{~nm}$ excitation wavelength with a grating, $600 / \mathrm{mm}$, $750 \mathrm{~nm}$ blaze. The spectrometer for $785 \mathrm{~nm}$ excitation wavelength was equipped with a deep depletion CCD since they show a better performance in the NIR region. Many biogenic materials show strong fluorescence using an excitation wavelength of $532 \mathrm{~nm}$, which is often reduced using one of $785 \mathrm{~nm}$. The advantage of an excitation wavelength of $532 \mathrm{~nm}$ on the other side is the lager spectral range covered during one measurement, making it possible to measure vibrational modes down to $70 \mathrm{~cm}^{-1}$ (typical for lattice vibrations of inorganic compounds) and up to $3600 \mathrm{~cm}^{-1}$ (typical for vibrational modes of functional groups like $=\mathrm{CH}_{2}, 3000$ $3200 \mathrm{~cm}^{-1}$ (e.g. Smith et al., 2005)) simultaneously. If an edge filter cutting off very close to the excitation wavelength is used, phase identification of calcium carbonates is straight forward, using their internal and external vibration modes (Bischoff et al., 1985; Behrends et al., 1995). The identification of organic compounds is done via the vibrational modes of their functional groups and is less straight forward, since the vibrations strongly depend on their interaction with their nearest environment. However, we will demonstrate in the Results and Discussion section, which information can be obtained from the Raman spectra.

The spectral analysis and imaging processing was performed using the WITecProject software (version 2.04, WITec GmbH, Germany). The peak positions given are determined using the "Mulipeak Fitting 2" routine of IGOR Pro using a Gauss shape for the fitting (version 6.11, WaveMetrics, Inc. USA).

\section{Results and discussion}

\subsection{Spatial distribution of mineral phases and crystallographic orientation}

Within the spectral dataset of scan1a performed across the zone of progressive transition between outer and inner shell layer (compare structures shown in Fig. 1c), calcite and aragonite could be identified. Calcite was identified using the two lattice modes (translation mode $\mathrm{T}_{\mathrm{c}}, 155 \mathrm{~cm}^{-1}$ and librational mode $\mathrm{L}_{\mathrm{c}}, 282 \mathrm{~cm}^{-1}$ ) and the two internal modes (in-plane band $v_{4}, 711 \mathrm{~cm}^{-1}$ and symmetric stretch $v_{1}, 1085 \mathrm{~cm}^{-1}$ ) (Fig. 2a). Aragonite was identified by the two lattice modes (translation mode $\mathrm{T}_{\mathrm{a}}, 152 \mathrm{~cm}^{-1}$ and librational mode $\mathrm{L}_{\mathrm{a}}$, $206 \mathrm{~cm}^{-1}$ ) and the two internal modes (in-plane band $v_{4}$, $705 \mathrm{~cm}^{-1}$ and symmetric stretch $v_{1}, 1085 \mathrm{~cm}^{-1}$ ) (Fig. 2a). The peak positions are in very good agreement with the published literature values (Behrends et al., 1995) and standard materials (information on the standard material used can be found in Kranz et al. (2010)). For aragonite, two significant different spectra could be identified within the spectral dataset, having identical peak positions but different ratios between the peak belonging to the $\mathrm{T}_{a}$ mode and the peaks belonging to the $\mathrm{L}_{\mathrm{a}}, v_{4}$, and $v_{1}$ mode. The latter is caused by different crystallographic orientation of the aragonite crystals (from here on referred to as aragonite_a and aragonite_b). In this study the differences in the Raman spectra related to the crystal orientation are only used to visualize qualitative changes in orientation within the structure. However, it should be noted that polarized Raman microscopy can provide in depth crystallographic information. Details on the physical background can be found in the literature (e.g. Hopkins and Farrow, 1985). The separate maps of the spatial distribution of calcite (b), aragonite_a (c), and aragonite_b (d) and a composite of all three maps (e) is given in Fig. 2. The analysis of the spectral dataset of the depth scan (scan1b) performed along the transect shown in Fig. 2e identifies the presence of aragonite and calcite as the only two mineral phases (Fig. 2f). The transition between calcite and aragonite phases is found to be sharp and oblique; however, a zone presenting no specific crystallographic orientation, $\sim 10 \mu \mathrm{m}$ thick, is found at the very beginning of the aragonite layer, before the alternation between aragonite $\mathrm{a}$ and $\mathrm{b}$ orientations starts. 
Table 1. Experimental parameters of the different mappings performed by means of confocal Raman microscopy.

\begin{tabular}{lcccccc}
\hline label & scan type & Size $(\mu \mathrm{m})$ & points per line & objective & wavelength $(\mathrm{nm})$ & integration time $(\mathrm{s})$ \\
\hline scan1a & high resolution & $170 \times 170$ & $450 \times 450$ & $100 \times 0.9$ & 785 & 0.2 \\
scan1b & depth profile & $100 \times 20$ & $200 \times 40$ & $100 \times 0.9$ & 785 & 0.1 \\
scan2a & high resolution & $175 \times 175$ & $450 \times 450$ & $100 \times 0.9$ & 532 & 0.2 \\
scan2b & large area & $1500 \times 700$ & $450 \times 450$ & $20 \times 0.4$ & 532 & 0.1 \\
scan1c & high resolution & $175 \times 175$ & $450 \times 450$ & $100 \times 0.9$ & 532 & 0.2 \\
\hline
\end{tabular}
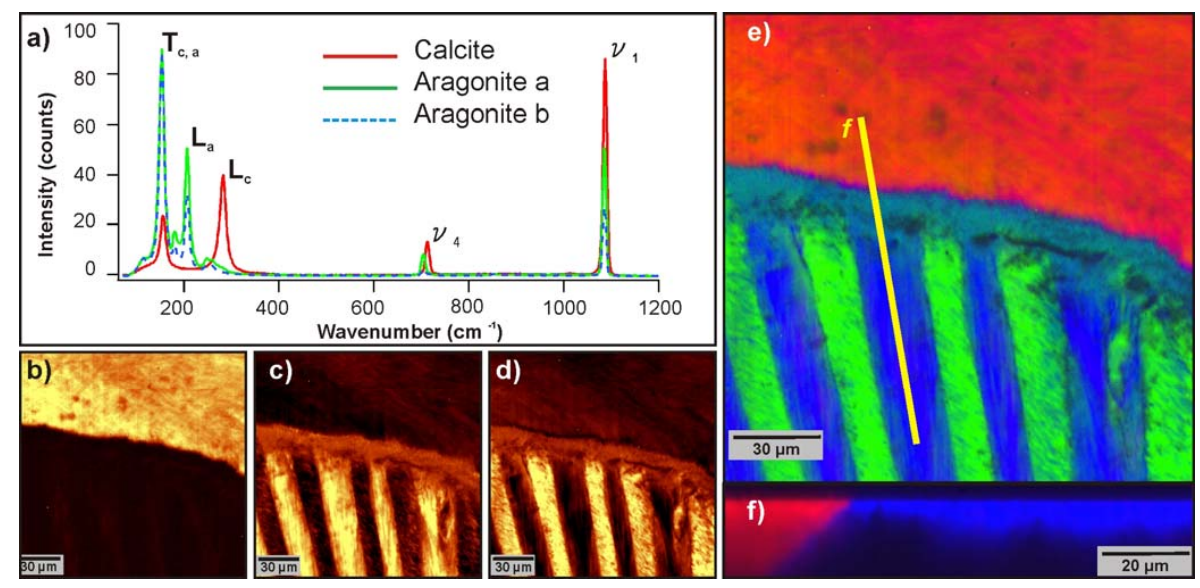

Fig. 2. (a) Raman spectra of calcite and aragonite extracted from scanla (aragonite_a and aragonite_b are related to different crystallographic orientations). (b) Map showing the distribution of calcite across the area scanned in scanla (scale bar $=30 \mu \mathrm{m})$. (c) Map showing the distribution of aragonite_a across the area scanned in scan1a (scale bar $=30 \mu \mathrm{m}$ ). (d) Map showing the distribution of aragonite_b across the area scanned in scan1a (scale bar $=30 \mu \mathrm{m}$ ). (e) False color composite of maps b, c, and d. Line f marks the transect, along which a depth scan (scan1b) was performed. (f) False color composite showing the vertical distribution of calcite and aragonite along transect $\mathrm{f}$ (Fig. 2e) determined from scan $1 b$.

The distribution of aragonite having two different crystallographic orientations as shown in Fig. 2c and d was obtained using the complete spectral information of the aragonite spectra (using the basic analysis routine of the WITec Project software package). The same information can be obtained by analyzing only the peak area of the two lattice peaks of aragonite (translation mode $\mathrm{T}_{\mathrm{a}}, 152 \mathrm{~cm}^{-1}$ and librational mode $\mathrm{L}_{\mathrm{a}}, 206 \mathrm{~cm}^{-1}$ ) as illustrated in Fig. $3 \mathrm{a}$, b, and c. It can even be seen that the map based on the intensity distribution (peak area) of only one peak reveals details in the transition zone (Fig. 3a and b) not seen in the map based on the complete spectral information (Fig. $2 \mathrm{c}$ and d). The mineral phase in the upper dark area of Fig. $3 \mathrm{~d}$ is calcite.

Our results are in good agreement with the known structure of the shell of Nerita undata: a calcite outer layer, very irregularly shaped, as well as a systematic alternate orientation of aragonite lamellae within the inner layer. The sharp change of orientation in aragonite strictly corresponds to observations using PLM with crossed polars (Fig. 1d). However, new data can be highlighted: the lateral resolution of the scan, $(\sim 300 \mathrm{~nm})$, reveals that the change of mineralogy is al- most instantaneous, as it occurs in less than a micron, which emphasise the close control exerted over the mineral phase deposited at each growth step. But the change of microstructural arrangement is not as immediate: the classical interspersed orientation of first order crossed-lamellae can only be established after several micrometers (a few growth increments) of a seemingly homogeneous aragonite layer with no particular orientation.

\subsection{Organic compounds}

Raman spectra of inorganic compounds like calcite and aragonite consist of relatively few peaks. These peaks can easily be attributed to the different vibrational modes using the Raman spectra of standard materials. Also the identification of organic molecules, which exhibits a large number of Raman peaks is straight forward as long as a reference Raman spectra is available. But the identification of complex organic molecules like the ones present in biogenic materials is difficult, since standards of these dedicated compounds are not available. However, even though not all peaks in such a complex spectrum can be identified, it is often possible to use the 

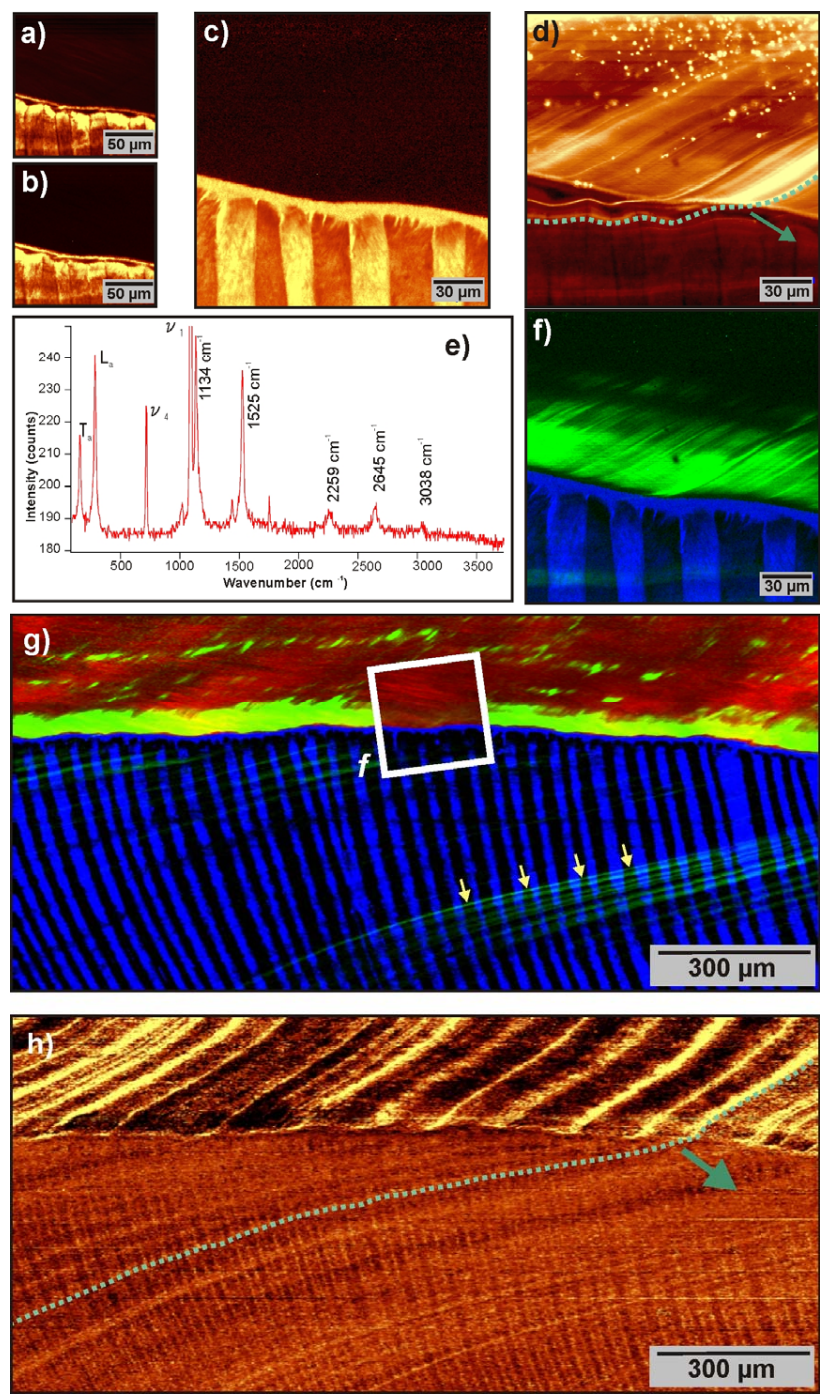

Fig. 3. (a) Map showing the intensity distribution (peak area) of the lattice peak of aragonite (translation mode $\mathrm{T}_{\mathrm{a}}$ at $152 \mathrm{~cm}^{-1}$ ) extracted from scan2a. (b) Map showing the intensity distribution of the lattice peak (peak area) of aragonite (librational mode $\mathrm{L}_{\mathrm{a}}$, $206 \mathrm{~cm}^{-1}$ ). (c) Map calculated from the ratio of map 3a and $3 \mathrm{~b}$. (d) Map showing the intensity distribution of the background intensity (between $2400 \mathrm{~cm}^{-1}$ and $2500 \mathrm{~cm}^{-1}$ ) related to the fluorescence of the sample. Dotted-line marks one growth layer and arrow marks the direction of growth. (e) Raman spectra extracted from scan 2 a showing the typical aragonite spectra and the RR peaks related to the presence of polyenes. (f) Map calculated from scan2a showing the distribution of the polyenes (green) (g) Map showing the distribution of calcite (red), aragonite_a (black), aragonite_b (blue), and polyenes (green) as extracted from scan $2 b$. The area f indicates the area in, which the previous scan (scan2a) was performed. The arrows in the aragonitic domain highlight where polyenes visualize the growth lines of the shell. (h) Map showing the change in Full Width Half Maximum (FWHM) of the symmetric stretch $v_{1}$ of carbonate group at $1085 \mathrm{~cm}^{-1}$ extracted from scan $2 \mathrm{~b}$. Dotted-line marks one growth layer and arrow marks the direction of growth. characteristic peak position belonging to a functional group to identify its presence. - $\mathrm{CH}$ groups for example, present in many organic compounds, show characteristic Raman bands (in the range between $2850-3000 \mathrm{~cm}^{-1}$ ), which results from their stretching vibration (Smith et al., 2005). It has to be noted that the amount of organic material present in biogenic calcium carbonates is very low, and often the very weak Raman peak of a functional group like $-\mathrm{CH}$ are the only indication for the presence of organic compounds. The next sub-sections describe the information on organic molecules, which can be obtained by analyzing the different spectral datasets measured (Table 1).

\subsubsection{Fluorescence}

Fluorescence induced by organic molecules often represents a severe problem in Raman microscopy. On the other hand, mapping the distribution of fluorescence can reveal information not obtained by the analysis of pronounced peaks. To do so, the intensity within an area containing no pronounced peaks should be chosen (for this sample $2400 \mathrm{~cm}^{-1}-2500 \mathrm{~cm}^{-1}$ ). This was done for the spectral dataset of scan 2 a before any background subtraction was applied. The areal distribution of the fluorescence obtained in the area of scan $2 \mathrm{a}$ is shown in Fig. 3d. Although no distinction can be made between organic classes, strong banding within the calcitic layer can be identified, which can also be followed within the aragonitic layer, even though more faintly marked. These bands correspond exactly to the growth layering of the shell. Irregularities seen in the upper part of Fig. 3d are most probably artifacts from the polishing process during, which aggregates of organic particles where formed.

\subsubsection{Pigments; Resonance Raman spectroscopy}

After the areas showing enhanced fluorescence have been identified (Fig. 3d) the spectral dataset scan2a was examined in these regions. The Raman spectra (Fig. 3e) in some regions of enhanced fluorescence showed several peaks (1019, $1134,1525,2259,2645$, and $3038 \mathrm{~cm}^{-1}$ ), which are not related to the spectra of calcite or aragonite, but are characteristic for Resonance Raman (RR) spectra from molecules presenting a central polyenic chain (as in $\beta$-carotene). Such molecules have been described to be present in some biogenic carbonates, and are usually identified as pigments close to polyenes or carotenoids (Urmos et al., 1991; Hedegaard et al., 2005; Fritsch and Karampelas, 2008). Intensity of the RR bands of these pigments is enhanced compared to the bands caused by the carbonate matrix. The reason for the latter is the resonant coupling of vibrational and electronic transitions with the laser source, which makes it possible to detect very small traces of pigments (down to $10^{-8} \mathrm{M}$ ) present within the sample (Merlin, 1985). Some authors attributed very similar RR bands in biogenic carbonates to 
carotenoids (Merlin, 1985; Urmos et al., 1991; Fritsch and Karampelas, 2008). However, more specific studies (Hedegaard et al., 2005; Fritsch and Karampelas, 2008; Karampelas, 2008) highlight a slight shift from carotenoids standard RR bands, that can be induced by the length of the polyenic chain, number of functional groups attached, or cis/trans- conformations. These results highlight the potential complexity of pigment identification within biogenic carbonates, which can present assemblages composed by several polyenic pigments (Karampelas, 2008). Using the relation between the positions of $\mathrm{C}-\mathrm{C}$ single bond and $\mathrm{C}=\mathrm{C}$ double bond peaks established by Hedegaard et al. (2005) for some all-trans polyenes with various chain lengths and several carotenoids, we consider that these peaks in Nerita undata, shown at 1134 and $1525 \mathrm{~cm}^{-1}$ respectively, are most probably produced by polyenes with chains of $\sim 9-10$ conjugated double bonds and terminal $-\mathrm{CH}_{3}$ groups. The RR effect depends on the wavelength of the laser source (Fritsch and Karampelas, 2008) and in our sample RR peaks could only be observed using the $532 \mathrm{~nm}$ excitation wavelength, but not with $785 \mathrm{~nm}$ excitation wavelength. Since these six peaks have shown to be present in constant ratios to each other one peak $\left(1525 \mathrm{~cm}^{-1}\right)$ was chosen representative to map their distribution (green area Fig. 3f). Plotting the distribution of the polyenes together with the mineralogical phases at high areal resolution, gives significant new insights on the modalities of shell formation. The layers in Fig. $3 \mathrm{~d}$ and $3 \mathrm{~h}$ match the typical growth layering that is universally found within biogenic calcium carbonate structures (e.g. Cuif et al., 2011). One growth layer (such as marked by the dotted line in Fig. 3d) corresponds to the exact position of the mantle (i.e. the mineralizing tissue), when it was mineralizing the underlying parts of the shell. This highlights the minute specialization of different areas of the mineralizing tissue, having distinct secretory activity. At a given time, this tissue can thus be easily separated in: (i) A outermost part that produces a calcite layer, poor in polyenes. (ii) A small section, $\sim 40 \mu \mathrm{m}$ wide, that produces calcite rich in polyenes. (iii) A section, $\sim 10 \mu \mathrm{m}$ wide, which produces aragonite not showing the typical crossed lamellar structure containing no polyenes. (iiii) A wider section that produces aragonite with a crossed-lamellar structure, still poor in polyenes. Within this aragonitic part the polyenes are layered over distances covering several hundred of $\mu \mathrm{m}$ along the mantle (arrows in Fig. $3 \mathrm{~g}$ ): this indicates that they are secreted by a large area of the mantle for short time pulses. In this area of the mantle, polyenes secretion is therefore not continuous, as opposed to the continuous secretion described above (ii). This feature, again, illustrates the possibility to reveal information on the chronological sequence of secretory activities of the mineralizing tissue, not revealed by other methods so far.

As can be seen from Fig. 3g, which was prepared from the large area scan $2 b$ (including the area in which scan2a was performed), the polyenes are strongly sensitive to the Raman measurement and can easily be bleached out of the
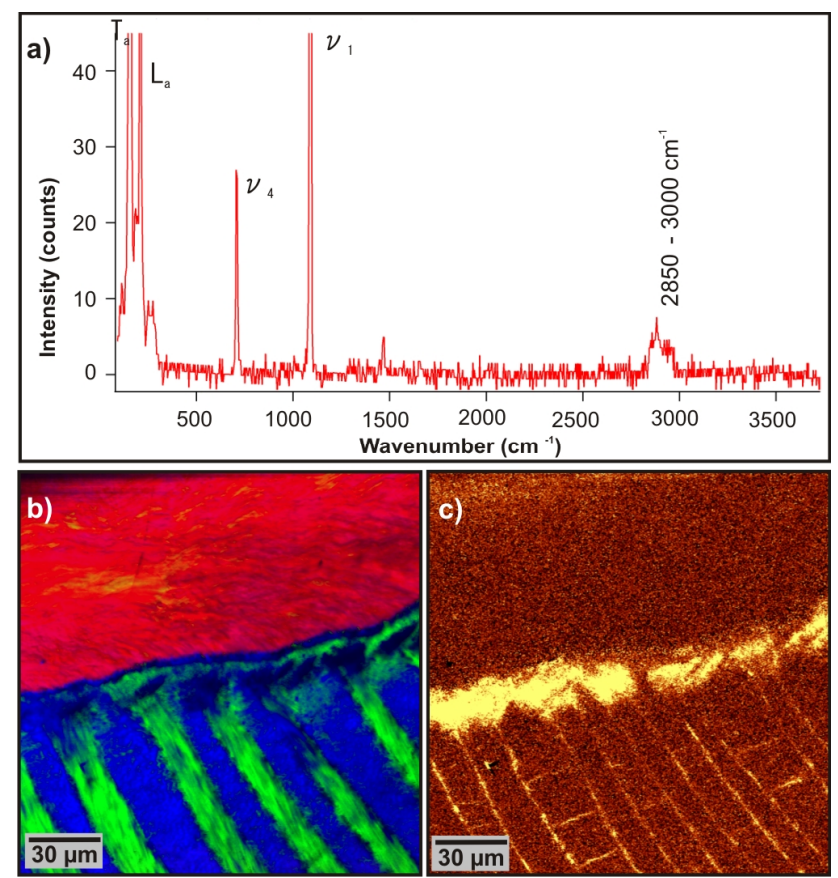

Fig. 4. (a) Raman spectra extracted from scan 1c showing the typical aragonite spectra and peaks between $2850-3000 \mathrm{~cm}^{-1}$, which correspond to the spectral range for $-\mathrm{CH}$ groups stretching vibrations. (b) Map showing the intensity distribution of calcite (red), aragonite_a (green), and aragonite_b (blue) extracted from scan1c. (c) Map showing the intensity distribution of the peak between 2850$3000 \mathrm{~cm}^{-1}$, which correspond to the spectral range for $-\mathrm{CH}$ groups stretching vibrations as extracted from scan $1 \mathrm{c}$.

sample surface (area f Fig. 3g). Some of the above described details could not be visualized in the high resolution scan, which demonstrates that large area scans are needed for a good overview of the structures present. On the other hand, like it will be shown in the next section, some information can only resolved performing a scan with high areal resolution.

\subsection{3 - CH groups}

The spectral analysis of scan $1 \mathrm{c}$ was used to determine the mineralogical domains (Fig. 4b). The latter show the same distribution described for the other scans. However, in addition to the peaks belonging to the calcium carbonate phases additional peaks are observed between $2850-3000 \mathrm{~cm}^{-1}$ (Fig. 4a), which correspond to the spectral range for $-\mathrm{CH}$ groups stretching vibrations (Smith et al., 2005). A map of this spectral range reveals the presence of highly enriched zones just after the calcite to aragonite transition, as well as their presence within the inner layer (Fig. 4c). Again, a close comparison with the mineralogical information reveals that the compounds containing $-\mathrm{CH}$ groups would be preferentially located between first order lamellae or within the homogeneous aragonitic zone that follows the calcite-to- 
aragonite transition. It should be noted that the presence of $-\mathrm{CH}$ groups could not be measured in all scans performed in this study, suggesting that organic molecules are very sensitive to sample preparation.

\subsubsection{Full width half maximum}

The mapping of the Full Width Half Maximum (FWHM) of the symmetric stretch $v_{1}$ of carbonate group at $1085 \mathrm{~cm}^{-1}$ reveal very sharp lines within the calcitic domains (Fig. 3h), which are also visible in the aragonitic domains, even though less pronounced. Surprisingly these growth lines visible in the aragonitic domains correspond partly to the growth lines visualized by the polyenes (see arrows in Fig. 3g). Although it is not clear at the moment what causes these changes in the FWHM of the peak related to the symmetric stretch $v_{1}$ of carbonate group at $1085 \mathrm{~cm}^{-1}$, this feature could also be used to follow the growth layering of the shell.

\subsection{Evaluation of experimental parameters}

In this section we will summarize how sample preparation and experimental parameters affect the results obtained by CRM when measuring polished cross sections of Nerita undata. This information will help to identify important aspects, which have to be considered if CRM measurements are performed on biogenic carbonates.

1. RR peaks of polyenes are only observed using an excitation wavelength of $532 \mathrm{~nm}$ but not $785 \mathrm{~nm}$.

2. Both wavelengths (532 and $785 \mathrm{~nm}$ ) could be used without inducing strong fluorescence. With dedicated studies using different excitation wavelengths and looking at slight shifts or changes of intensities of polyenic chains bands (as suggested by Fritsch and Karampelas, 2008), it might therefore be possible to further investigate the complexity of multiple pigments assemblages and to determine their areal distribution.

3. Polyenes are easily bleached away during the measurements.

4. Mapping the fluorescence distribution across the sample gives important structural information even though an identification of the substances causing it is not possible.

5. Calculating the FWHM of the peaks related to the symmetric stretch $v_{1}$ of carbonate group at $1085 \mathrm{~cm}^{-1}$ reveals structures related to the growth layering. In some parts of the samples these lines correlate with the position of the polyenes, but do not disappear when the polyenes are bleached away.

6. The areal distribution of $-\mathrm{CH}$ groups could only be determined in one of the samples. This demonstrates that sample preparation (one being a thin section the other a thick section) may alter the sample. Therefore it will be necessary to test different methods of sample preparation to determine, which steps during the preparation of a polished surface alter the measured Raman spectra.

\section{Conclusions}

Our results highlight the potential of CRM for the identification of micro-structural patterns within biogenic carbonates, including mineral phase detection and crystallographic orientation contrasts, as well as distribution of organic content and possible leads toward their identification.

When applied to the shell of Nerita undata, a detailed description of modalities of shell deposition can be drawn, involving the variation of secretory activity of different organic molecules from distinct mantle areas through time, as well as a very close control over mineral phase selection and orientation.

Further investigations, dedicated to a better characterization of organic molecules and functional groups (with the use of simple proteins, lipids and sugars standards, or even separated shell extracts) are of course mandatory, as well as investigations on their possible interactions with mineral phases: this way only, complex features, like the variation of FWMH of $\mathrm{CO}_{3}^{2-}$ symmetrical stretch band accordingly to growth layering directions, could be fully explained.

Organic molecules are found to be very sensitive to laser exposition, and can be easily altered or bleached away, urging the need to develop more cautious preparation and measurement protocols (e.g. low laser energy).

Optimizing the instrumental parameters for biogenic carbonates, CRM can be considered to give new insight into the structural composition of e.g. coral skeletons, foraminifera tests, fish otoliths etc., enabling a systematic comparison between taxa/phyla. The information on the structural composition will help to better evaluate the impact of artificially altered culturing conditions on biogenic marine carbonates.

Acknowledgements. This research was supported by the DFG by grant NE 1564/1-1 (SPP 1158), the European Commission through grant 211384 (EU FP7 "EPOCA"), and the German Federal Ministry of Education and Research (BMBF, FKZ 03F0608, "BIOACID").

Edited by: T. Treude 


\section{References}

Behrends, G., Kuhn, L. T., Ubic, R., and Heuer, A. H.: Raman Spectra of Vaterite Calcium Carbonate, Spectros. Lett., 28, 983995, 1995.

Bischoff, W. D., Sharma, S. K., and Mackenzie, F. T.: Carbonate ion disorder in synthetic and biogenic magnesian calcites: a Raman spectral study, American Mineralogist, 70, 581-589, 1985.

Bøggild, O. B.: The shell structure of the molluscs. D. Kgl. Danske Vidensk. Selsk. Skr., naturvidensk. og mathem., 9, 231-326, 1930.

Borzecka-Prokop, B., Weselucha-Birczynska, A., and Koszowska, E.: MicroRaman, PXRD, EDS and microscopic investigation of magnesium calcite biomineral phases, The case of sea urchin biominerals, J. Mol. Struc., 828, 80-90, 2007.

Crenshaw, M. A.: The soluble matrix from Mercenaria mercenaria shell. Biomineralization, 6, 6-11, 1972.

Cuif, J.-P., Dauphin, Y., and Sorauf, J. E.: Biominerals and Fossils Through Time, Cambridge University Press, 2011.

Cusack, M., Dauphin, Y., Cuif, J.-P., Salomé, M., Freer, A., and Yin, H.: Micro-XANES mapping of sulphur and its association with magnesium and phosphorus in the shell of the brachiopod, Terebratulina retusa, Chem. Geol., 253, 172-179, 2008.

Dauphin, Y., Ball, A. D., Cotte, M., Cuif, J.-P., Meibom, A., Salome, M., Susini, J., and Williams, C. T.: Structure and composition of the nacre-prisms transition in the shell of Pinctada margaritifera (Mollusca, Bivalvia), Anal. Bioanal. Chem., 390, 1659-1669, 2008.

Dauphin, Y., Brunelle, A., Cotte, M., Cuif, J., Farre, B., Laprévote, O., Meibom, A., Salomé, M., and Williams, C.: A Layered Structure in the Organic Envelopes of the Prismatic Layer of the Shell of the Pearl Oyster Pinctada margaritifera (Mollusca, Bivalvia), Micros. Microanal., 16, 91-98, 2010.

Dauphin, Y. and Denis, A.: Structure and composition of the aragonitic crossed lamellar layers in six species of Bivalvia and Gastropoda, Comp. Biochem. Physiol., 126, 367-377, 2000.

Farre, B., Brunelle, A., Laprévote, O., Cuif, J. P., Williams, C. T., and Dauphin, Y.: Shell layers of the black-lip pearl oyster Pinctada margaritifera: Matching microstructure and composition, Comp. Biochem. Phys. B, 159, 131-139, 2011.

Farre, B. and Dauphin, Y.: Lipids from the nacreous and prismatic layers of two Pteriomorpha Mollusc shells, Comp. Biochem. Phys. B, 152, 103-109, 2009.

Fritsch, E. and Karampelas, S.: Comment on "determination of carotenoid as the purple pigment in Gorgonia ventalina sclerites using Raman spectroscopy" [Leverette et al., Spectrochim. acta A, 69 (2008) 1058-61]. Spectrochim. acta, doi:10.1016/j.saa.2008.1005.1004, 2008.

Gregoire, C.: Further studies on structure of the organic components in mother-of-pearl, especially in Pelecypods, Bull. Inst. Roy. Sci. nat. Belg., 36, 23, 31-22, 1960.

Hedegaard, D. C., Bardeau, C., and Chateigner, J. F.: Molluscan shell pigments: an in situ resonance raman study, J. Molluscan Stud., 72, 157-162, 2005.

Heim, C., Sjövall, P., Lausmaa, J., Leefmann, T., and Thiel, V.: Spectral characterisation of eight glycerolipids and their detection in natural samples using time-of-flight secondary ion mass spectrometry, Rapid Commun. Mass Sp., 23, 2741-2753, 2009.

Hild, S., Marti, O., and Ziegler, A.: Spatial distribution of calcite and amorphous calcium carbonate in the cuticle of the terrestrial crustaceans Porcellio scaber and Armadillidium vulgare, J. Struc. Biol., 163, 100-108, 2008.

Hopkins, J. B. and Farrow, L. A.: Raman microprobe determination of local crystal orientation, J. Appl. Phys., 59(4), 1103-1110, 1985.

Karampelas, S.: Etude du changement de couleur des perles par traitement, UFR Sciences et techniques, Université de Nantes, Nantes, 2008.

Kobayashi, I.: Introduction to the shell structure of bivalvian molluscs, Earth Sci., 73, 1-12, 1964.

Kobayashi, I. and Akai, J.: Twinned aragonite crystals found in the bivalvian crossed lamellar shell structure, J. Geol. Soc. Japan, 100, 177-179, 1994.

Krampitz, G., Engels, J., and Cazaux, C.: Biochemical studies on water-soluble proteins and related components of gastropod shells, in: The mechanisms of mineralization in the invertebrates and plants, edited by: Watabe, N. and Wilbur, K. M., The Belle Baruch Library in Marine Science, Univ. of South Carolina Press, 155-173, 1976.

Kranz, S. A., Wolf-Gladrow, D., Nehrke, G., Langer, G., and Rost, B.: Calcium carbonate precipitation induced by the growth of the marine cyanobacteria Trichodesmium, Limnol. Oceanogr., 55, 2563-2569, 2010.

McCrea, J. M.: On the Isotopic Chemistry of Carbonates and a Paleotemperature scale, The Journal of Chemical Physics, 18, 849857, 1950.

Melancon, S., Fryer, B. J., Ludsin, S. A., Gagnon, J. E., and Yang, Z.: Effects of crystal structure on the uptake of metals by lake trout (Salvelinus namaycush) otoliths, Can. J. Fish. Aquat. Sci., 62, 2609-2619, 2005.

Merlin, J. C.: Resonance Raman spectroscopy of carotenoids and carotenoid-containing systems, Pure Appl. Chem., 57(55), 785792, 1985.

Mutvei, H.: On the micro- and ultrastructure of the conchiolin in the nacreous layer of some recent and fossil molluscs, Stockholm Contr. Geol., 20, 1-17, 1969.

Nakahara, H. and Bevelander, G.: The formation and growth of the prismatic layer of Pinctada radiata, Calc. Tiss. Res., 7, 31-45, 1971.

Nudelman, F., Gotliv, B. A., Addadi, L., and Weiner, S.: Mollusk shell formation: mapping the distribution of organic matrix components underlying a single aragonitic tablet in nacre, J. Struct. Biol., 153, 176-187, 2006.

Royal Society: Ocean acidification due to increasing atmospheric carbon dioxide, Royal Society, 2005.

Samata, T., Sanguansri, P., Cazaux, C., Hamm, M., Engels, J., and Krampitz, G.: Biochemical studies on components of molluscs shells, The mechanisms of biomineralization in animals and plants, Proc. Third Intern. Biomin. Symp., edited by: Omori, M. and Watabe, N., Tokai Univ. Press, 37-47, 1980.

Smith, E., Dent, G., and Smith, A.: Modern Raman Spectroscopy: A Practical Approach, John Wiley \& Son, 2005.

Taylor, J. D., Kennedy, W. J., and Hall, A.: The shell structure and mineralogy of the Bivalvia. I. Introduction, Nuculacae - Trigonacae, Bull. Br. Mus. nat. hist. Zool., 3, 1-125, 1969.

Travis, D. F.: The structure and organization of, and the relationships between, the inorganic crystals and the organic matrix of the prismatic region of Mytilus edulis, J. Ultrastructure Res., 23, 183-215, 1968. 
Urey, H., Lowenstam, H., Eppstein, H., and McKinney, C.: Measurement of paleotemperatures and temperatures of the upper cretaceous of England, Denmark, and the southeastern united states, Geol. Soc. Amer. Bull., 62, 399-416, 1951.

Urmos, J., Sharma, S. K., and Mackenzie, F. T.: Characterization of some biogenic carbonates with Raman spectroscopy, Am. Mineralog., 76, 641-646, 1991.
Weiner, S. and Traub, W.: Macromolecules in mollusc shells and their functions in biomineralization, Phil. T. R. Soc. Lond. B, 425-434, 1984.

Wilmot, N. V., Barber, D. J., Taylor, J. D., and Graham, A. L.: Electron microscopy of molluscan crossed-lamellar microstructure, $\mathrm{P}$. T. R. Soc. Lond. B, 21-35, 1992. 